\title{
Textura Instrumental na Africa Ocidental: a Peça Agbadza
}

\author{
Marcos Branda Lacerda
}

Este artigo trata preferencialmente de um fenômeno ainda pouco observado na distribuição das partes fixas que constituem o conjunto instrumental Atsiấ, da população Ewe do sul de Ghana: ao contrário do que se supōe normalmente na literatura musicológica sobre este gênero da música africana, os instrumentistas não responsáveis pela parte solista podem introduzir eventualmente alteraçōes estruturais na textura de uma peça determinada. Procuro demonstrar também alguns conceitos básicos da música africana ocidental, e fazer um paralelo entre a forma de organização da textura instrumental na música iorubá e ewe. Concluindo o trabalho, apresento uma colaboração à discussão sobre os princípios que regulam a orientação rítmica dos executantes neste tipo de música.

\section{Conceitos básicos}

Em primeiro lugar, assume-se que todos os dançarinos e músicos de um conjunto instrumental da regiāo costeira da África Ocidental compartilham a sensação da presença de um valor periódico de duração, que chamamos de duração de referência.(1) Tal duração estaria submetida no decorrer de uma peça invariavelmente a uma divisão rítmica binária ou ternária. Realizaçóes redundantes deste valor de duração seriam aquelas expressas respectivamente nos exemplos (1) e (2), através do que denominamos de duraçöes de divisão.

A definiçäo de uma peça em razão da organizaçāo binária ou ternária de um valor fixo de referência $\epsilon$ importante no sentido em que os primeiros trabalhos sobre música percussiva da África Ocidental interpretavam as partes solistas de uma peça dada de maneira aditiva. A conseqüência disso foi uma questionável diferença na conceituação teórica de partes instrumentais fixas e solistas, isto $\varepsilon$, que estas partes funcionariam simultaneamente segundo preceitos teóricos diversificados.(2)

Tanto o sistema binário quanto o ternário admite uma divisão em duas fases da duração de referência: respectivamente $\delta$ e $\delta$. . No sistema ternário esta divisão é menos freqüente.

O tempo de uma peça $\epsilon$ dado pelo tempo de articulação da duração de referência. Este valor situa-se normalmente entre $d, d .=$ 80 - 120. Desta forma é possível a introdução dos valores $F$ (em binário) e $\mathcal{F}$ em ternário, em configurações rítmicas assimétricas ou em encadeamentos.

ritmo binário
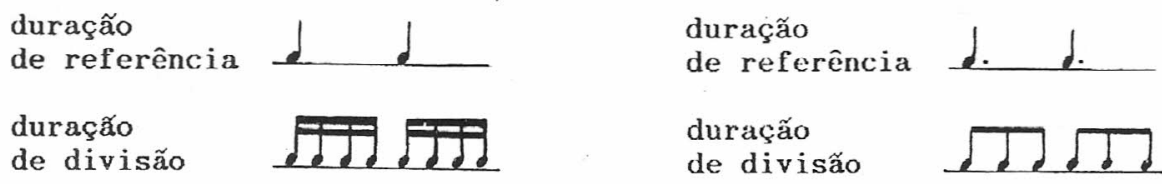
Atingindo uma peça tempos extremamente rápidos, estes valores passam a ser omitidos. Ao contrário, no caso de tempos extremamente lentos, eles podem ser submetidos a divisóes com valores inferiores.

Resta mencionar uma duração que possui a propriedade de interferir na regularidade binária ou ternária de uma peça, quando usada sucessivamente e não em configuraçōes rítmicas assimétricas, a qual denominamos duração die contraste: $\int$. (em binário) e J (em ternário).

Sintetizando, a música instrumental da África Ocidental utiliza prioritariamente as seguintes duraçōes, que aqui são dispostas de acordo com as duas bases rítmicas possíveis. Estas duraçōes podem ser entendidas tanto como valores concretos, assim como valores abstratos de orientação.

binário

$\int$ duraçấo de referência d.

As partes que compöem o conjunto instrumental percussivo da Africa Ocidental se dividem em dois grupos: o primeiro, do qual constam partes instrumentais fixas, e o segundo, constiturdo regularmente por um tambor solista. Eventualmente, uma parte instrumental do primeiro grupo pode interagir diretamente com o tambor solista, passando a fazer parte, em momentos previsíveis, do segundo grupo. A parte solista, normalmente responsável pela regiảo mais grave do espectro sonoro, é realizada na maioria das vezes pelo tambor-mãe, conforme o costume africano de associar o feminino aos tambores mais graves e maiores. As outras partes cabem aos tambores-suporte e, também, de acordo com a constituição especifica de uma orquestra, idiofones. A parte eventualmente intercambiante $\varepsilon$ realizada por um tambor de resposta, conforme a musicologia ewe.

\section{Textura instrumental}

A música instrumental percussiva da África Ocidental se organiza acentuadamente através da disposição periódica de configurações rítmicas. A esse tipo de estrutura chamamos modelo de periodicidade.(3) A interação dos modelos de periodicidade que compōem as partes do primeiro grupo instrumental acima mencionado denominamos textura. Os exemplos (4-5) referem-se à textura instrumental das peças Kiriboto do repertório batá da cidade iorubá de Pobè, na República Popular do Benin (exemplo (4)) e Atsiagbeko,(4) que consta do repertório Atsiā da população ewe do sul de Ghana (exemplo (5)).

$O$ conceito de modelo de periodicidade aplica-se igualmente à parte solista. Em momentos dados, o executante pode reter uma configuração rítmica repetidamente, associando-a ao resto de uma estrutura linear variada, ou mesmo mantendo-a de forma isolada em complementação ou contraste à textura. Modelos de periodicidade contrastantes são comuns na parte do tambor-mãe na música iorubá.

$O$ exemplo (6) foi extraído da execução de Lade Lade, do culto para Xangô em Sakete.

Dependendo do grau de complexidade de uma peça, ou mesmo do estilo de uma determinada orquestra, a textura rítmica pode ser organizada de modo tambem a fornecer subsidios à permanente orientação dos executantes segundo um ciclo métrico dominante. Nos exemplos acima, observa-se um modelo de periodicidade comum que serve a esta finalidade ( $J \zeta 丁 \zeta \supset\rfloor J$ ), cuja freqüência nos diferentes repertorios de inúmeras etnias africanas lhe valeu a designação específica de fórmula padrão (standard pattern).

Observe-se que no exemplo (6), a parte do aḱ consiste na repetiçāo de um segmento que ocupa toda a extensâo métrica compreendida por um ciclo de 4 duraçōes de referência. Com efeito, a este instrumento cabe regularmente a execuçāo de configuraçōes correspondentes ao ciclo métrico. Apenas no caso da fórmula padrão este instrumento cede ao omele abo a execução de um segmento de extensão métrica. As relaçốes métricas no estilo ewe serảo discutidas abaixo.

$\mathrm{Na}$ música batá ionubá, poucos são os exemplos em que uma unidade de tempo contrastante com a duração de referência sirva de base a uma configuração rítmica periodicamente disposta nas partes texturais. Ou seja, as partes que compöem a textura de uma peça no repertório batá se referem, regularmente, 
(4)

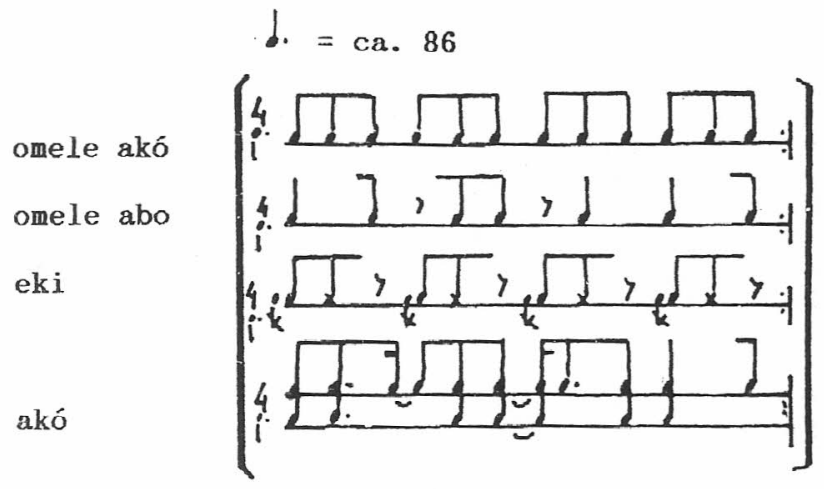

(5)

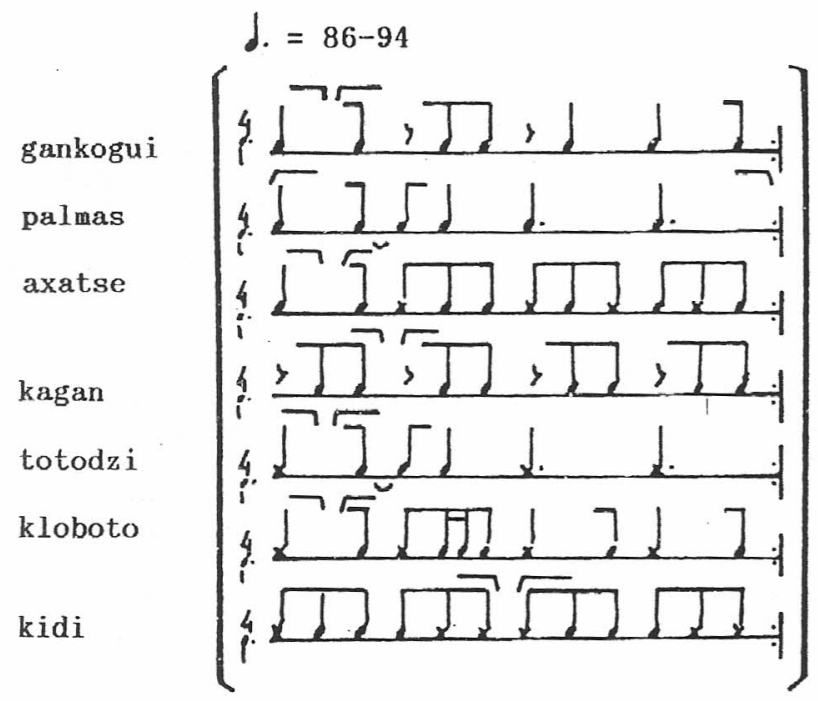

(6)

$$
\text { d. = ca. } 80 \quad 25-26
$$

omele akó

iya ilu

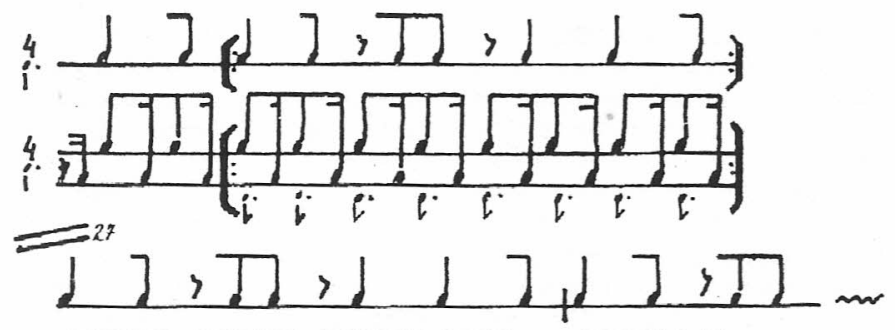

duracî̃o d: contraste

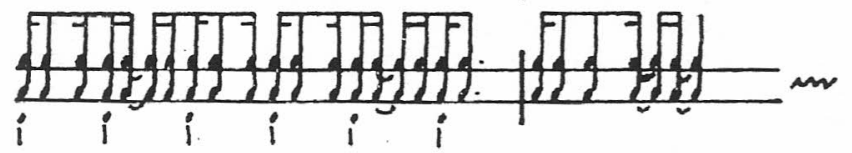

d่ไt

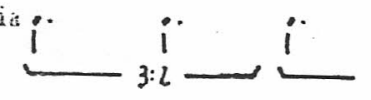


diretamente à duração de referência própria à base rítmica binária ou ternária dessa peça. Desta forma, o contraste polirrítmico fica reservado à relação entre eventuais momentos da parte do tambor-mãe e as partes texturais, como no ciclo 27 do exemplo (8).

O fenômeno rítmico de oposiçăao entre partes baseadas respectivamente na sucessão periódica da duração de referência e da duração de contraste, ou de seus respectivos múltiplos, recebeu a denominaçăo de ritmo cruzado (cross rhythrn). Praticamente, trata-se das relaçōes $2: 3,3: 2,4: 3$ e $3: 4$, respeitada a duração de divisão comum às duas partes.

O atributo "fixo" conferido às partes texturais justifica-se enquanto restrito ao contraste entre sua relativa rigidez e o maior grau de variabilidade na execução do solista. No decorrer de uma execução podem ser usadas variantes ornamentais, cuja introdução estaria a critério do músico tanto em razão de sua percepção das estruturas apresentadas pelo solista quanto por uma contribuição independente à configuração geral da textura.

Desta forma, observa-se uma participação extremamente exuberante do executante do tambor éki da orquestra batá de Pobè, se compararmos ao tipo de execução do mesmo tambor na orquestra de Sakéte. Ao contrário, as estruturas do tambor-mâe da orquestra de Sakété contribuem muito mais ao enriquecimento da textura do que se apresentam como contraste às partes fixas propriamente ditas. Particularmente a orquestra de Pobè apresenta variantes ornamentais nas partes dos tambores-suporte que implicam um adensamento da organização da textura.

Antes de passar à descrição das variaçóes de textura na peça Agbadza do repertório ewe, eu gostaria de revisar a afirmação feita acima de que no exemplo (4) duas partes - omele abo e ak 6 - ocupam a extensāo integral do ciclo métrico de quatro duraçōes de referência ( $J$. ).

A organização da parte do akó sugere um espaçamento regular de uma configuraçāo

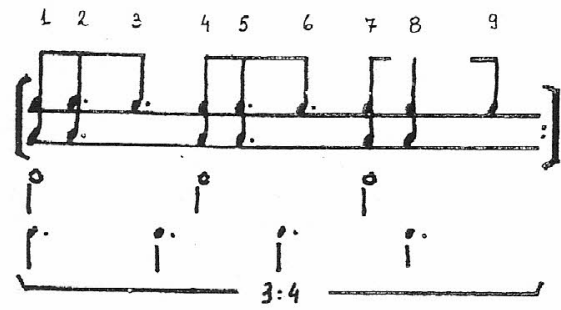

rítmica com base em um múltiplo da duração de contraste própria ao ritmo ternario ( $d \downarrow$ ), que gera a relação $3: 4$ com a latente sucessão de 4 duraççes de referência:

Isoladamente, uma tal configuração rítmica me parece extremamente complexa, considerando-se ainda que ela estaria sendo articulada $\mathrm{com}$ base na seqüência de duração de contraste ( J ), e não na seqüência de duração de referência forçosamente presente. A complexidade seria decorrente de o executante năo articular a batida isolada sobre a membrana aguda (batidas 3 e 6) no mesmo momento de articulação de uma duração de divisão $(\delta)$, como na batida 9. Esta última batida, redundante em relação à seqüência de duraçāo de divisão, denota exatamente o caráter linear - e não cíclico - da parte do akó no interior da extensão métrica, preparando para mais um ciclo métrico de 4 duraçōes de referência. A relação polirrítmica $4: 3$ (ritmo cruzado) entre a parte do akó e o ciclo de duração de referência, a meu ver neutralizada pelas batidas agudas, estaria plenamente caracterizada isolando-se apenas as batidas simultâneas nas duas membranas $(x)$.

Esta discussão tem também como finalidade acentuar uma primeira diferenciação entre os estilos iorubá e ewe. O primeiro se caracteriza por uma textura inequivocamente percebida em conjunção com a seqüência da duração de referência. No segundo, ao contrário, ritmos cruzados apresentam-se de forma permanente, resultantes tanto da relação das configuraçóes fixas dos instrumentos suporte quanto da relação destas com a seqüência de duração de referência. Além disso, mesmo admitindo-se a relação polirrítmica no exemplo iorubá acima, observe-se que o início do ciclo polirrítmico $4: 3$ - isto $\epsilon$, o momento de articulação simultânea das duas partes, coincide com o iń́cio da fórmula padrão executada pelo omele abo. Na música ewe, como veremos abaixo, ciclos polirrítmicos podem iniciar-se em pontos distintos da fórmula padrão, o que a torna sem dúvida alguma peculiar entre os estilos percussivos africanos.

\section{A peça Agbadza}

David Locke apresenta as partes texturais de Agbadza de maneira ligeiramente diferente da versão registrada por Richard Hill.(5) Nesta não constam as palmas, e a parte do tambor de resposta kidi configura-se de forma menos densa, mas estruturalmente idêntica (isto $\hat{\varepsilon}$, com o mesmo relacionamento com a parte da campana, o gankogui). Na versāo de Locke o tempo $\epsilon$ de $d .=120$, enquanto 
na versão de Hill de $\lfloor=$ ca.100. Finalmente, desta versão consta a participação da cabassa axatse,(6) da mesma forma como na textura de Atsiagbeko apresentada acima. Os exemplos (8-9) mostram a textura de ambas as versóes. $O$ conjunto $\epsilon$ complementado pelo tambor solista sogo, cuja participação será mencionada abaixo.
Na gravação de Hill, a textura de Agbadza mantém-se conforme o exemplo (8) durante os primeiros 59 ciclos métricos. No ciclo 60, o executante do kagan suprime o tempo de uma duração de contraste, antecipando a relação de sua parte com a parte do gankogui. A configuração antecipada se mantém até o ciclo 72 , o que já significa uma considerável alteração estrutural da textura (v. exemplo (10)).

$$
\text { Agbadza (Hi 11) }
$$
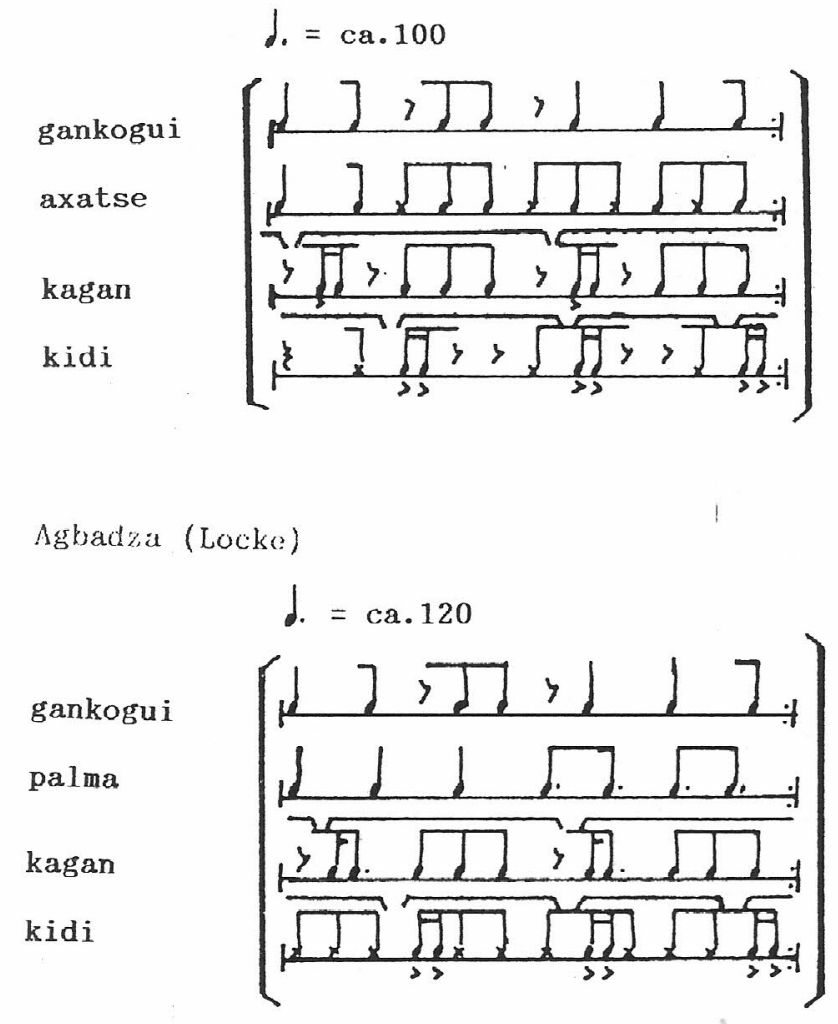

(10)

$60 \quad 61-71$
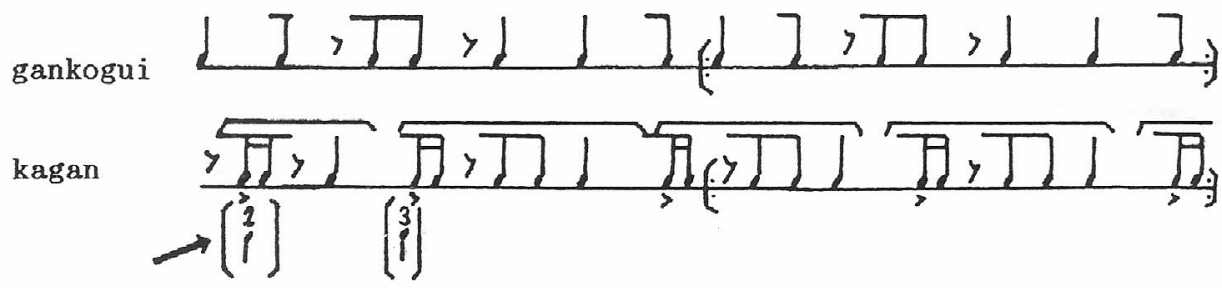
A seguinte alteração se dá na parte do kidi, 3 ciclos inteiros após a alteração do kagan. $O$ executante antecipa pelo mesmo tempo sua parte no ciclo 64, estabelecendo um paralelismo relativo com a parte do kagan até o ciclo 72. Com esta alteraçāo se perdem elementos essenciais de sua participação original na textura (v. exemplo (11)).

A próxima alteraçāo, no ciclo 72 , é a reversão da parte do kagan à sua posição original na textura. $O$ executante se utiliza do processo inverso, isto $\varepsilon$, ele estende o tempo de (11)
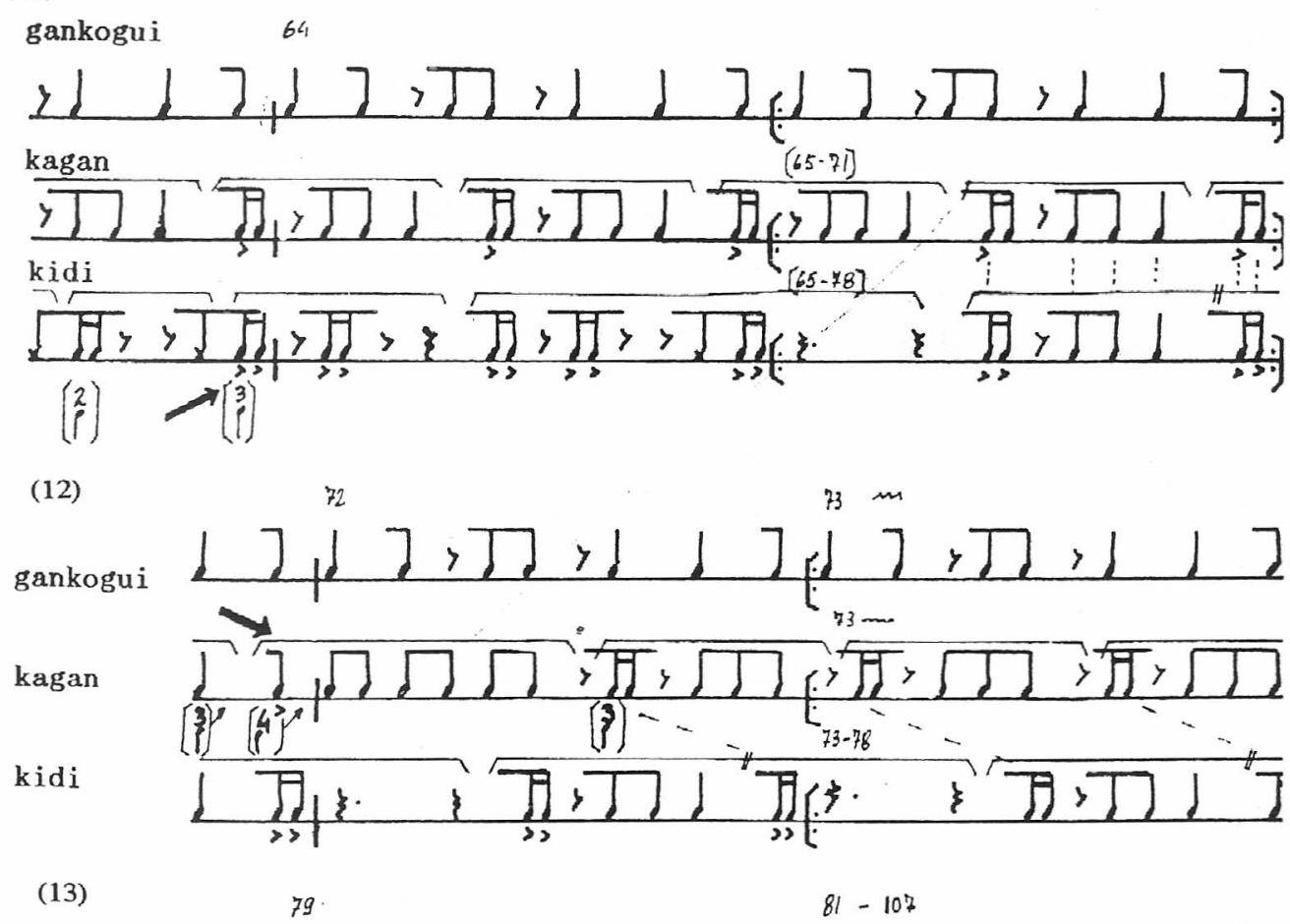

gankogui
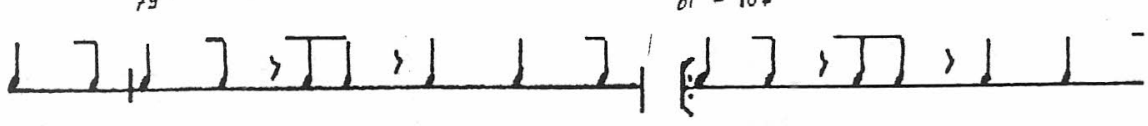

kagan
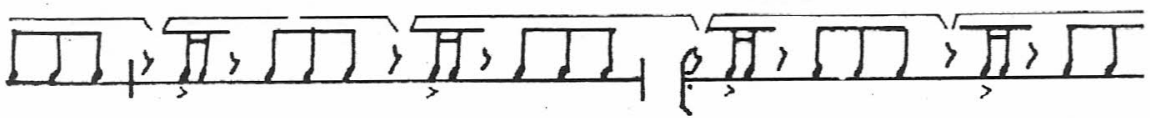

kidi
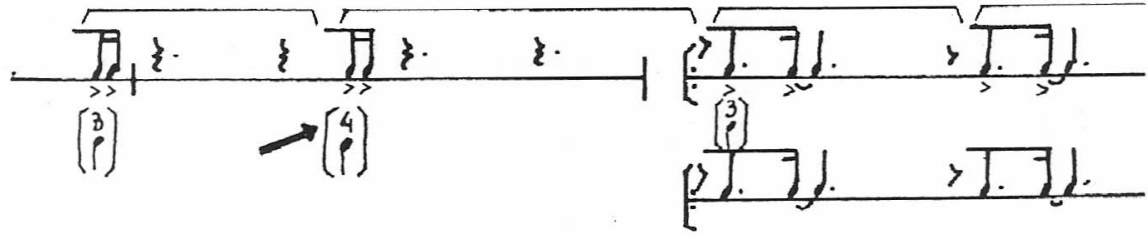

sogo

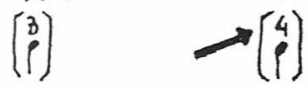


Finalmente, no ciclo 108, kidi e sogo passam a articular simultaneamente uma configuração rítmica introduzida pelo motivo anterior, permanecendo assim até o ciclo 125 , quando a gravação chega ao fim através da gradual diminuição de volume. Note-se que as duas batidas acrescentadas são paralelas à configuração do kagan (v. exemplo (14)).

A peça Agbadza ilustra a riqueza de relações rítmicas contidas na textura do estilo ewe. A notação adotada observa a presença teórica de duraçōes de referência, fáceis de se- rem deduzidas no estilo iorubá. Dispondo-se as configurações iniciais dos tambores suporte segundo suas qualidades métricas individuais terfamos as seguintes opçōes apontadas no exemplo (15).

Para dernonstrar o relacionamento polirrítmico das partes entre si e a sequêencia de duração de referência, poderíamos substituir estes motivos pelos valores de duração de toda a sua extensão e posição métricas e reescrever teoricamente a textura inicial conforme os exemplos $(16-17)$.

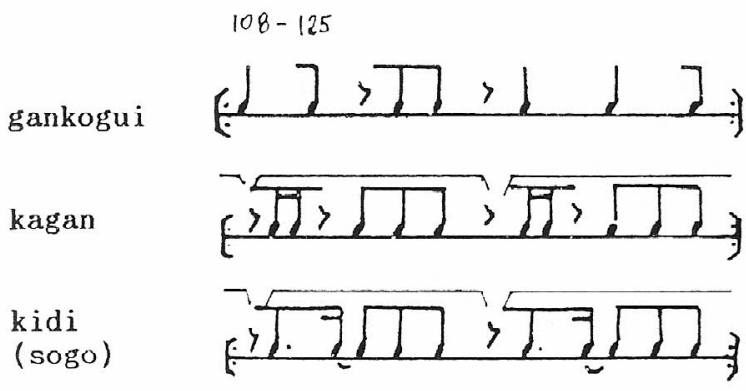

(15)

kagan

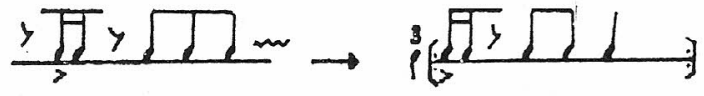

kidi

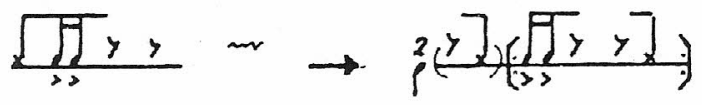

(16)

dur.ref.

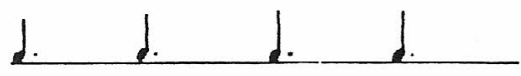

kagan

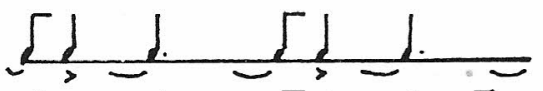

kidi

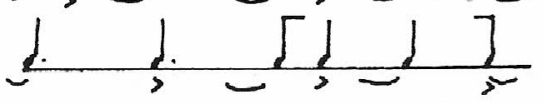

(17)

dur ref.

kidi

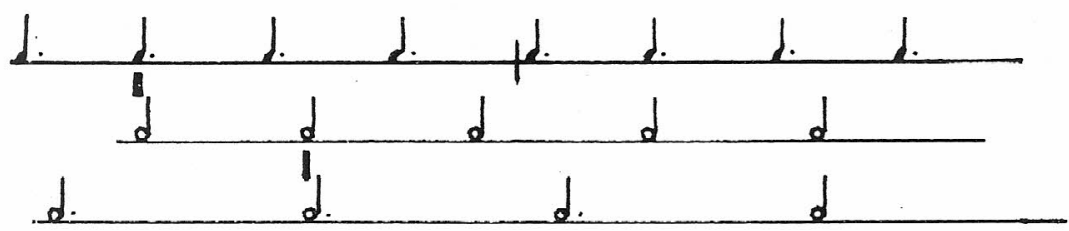


A textura de Agbadza contém, portanto, um ritmo cruzado na razão de 3:4 entre a parte do kidi e a seqüência de duração de referência, bem como de 4:3 entre a mesma parte e a parte do kagan.(7) Além disso, a parte do kagan relaciona-se $\mathrm{com}$ a seqüência de duração de referência de maneira regularmente sincopada.

A antecipação na parte do kagan no ciclo 60 , e a conseqüente alteração do comportamento do executante do kidi, provoca um empobrecimento da textura. A sua relação com a seqüência de duração de referência continua sendo regularmente sincopada, mas as relaçōes de ritmo cruzado anteriormente existentes foram eliminadas. Considerando-se que ela não possui o caráter ornamental a que se referem aqueles que mais se ocuparam desta música, $f$ possível que a alteração do kagan possa ser vista como um momentâneo "lapso" do executante. No entanto, $\varepsilon$ interessante notar de que maneira o conjunto resiste a essa mudança.

Eu gostaria ainda de ressaltar uma relação rítmica entre a seqüência de duração de referência e a seqüência resultante da decomposição dos valores de duração das configuraçóes do kagan e do kidi. O exemplo (18) demonstra um ritmo cruzado na razão de 3:2 entre as duraçōes de referência e aquela seqüência que chamamos de seqüência sincopada de duraçāo de contraste:(8)

Note-se que o ponto em que se encontram as batidas acentuadas do kagan e do kidi coincide com a batida 5 da fórmula padräo; gerando para ouvidos nāo africanos a percepção equivocada da parte do gankogui, expressa no exemplo (19). A posição da sequiência de duração de referência em relaçăo a esta configuração não coincide com aquela considerada correta.

$O$ relacionamento entre a seqüência de duração de referência e a seqüência sincopada de duração de contraste $\epsilon$ mais remoto do que aquele determinado pela extensão total das configuraçóes rítmicas, expresso nos exemplos (16-17). No entanto, ele passa a ser relevante levando-se em conta também a contribuição do tambor solista.

A parte do sogo na gravação de Hill caracteriza-se pela execução de configurações semelhantes às do ciclo 10 e 11 dos exemplos (20-21), que coincidem com a acentuação do kagan. A introduçāo desta frase, que pode apresentar-se bastante variada, se dá após a execução de modelos de periodicidade, de extensōes diversas, muitas vezes conforme a acentuação do kidi (ciclos 12-13 e 14-15). Esta constante mudança(9) faz com que a seqüência sincopada de duração de contraste, comum a ambas as partes, emerja como elemento articulador em oposiçāo à seqüência de duração de referência, ou de durações correspondentes à extensão total das figuras dos tambores suporte (ver exemplo (20)).

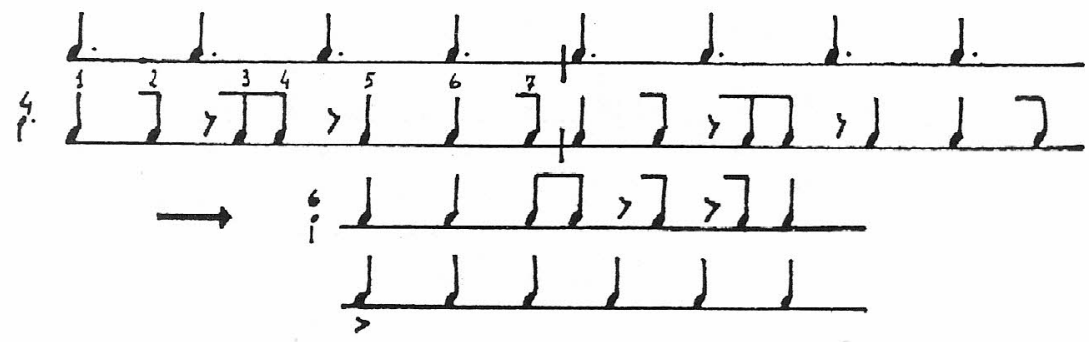

(19)

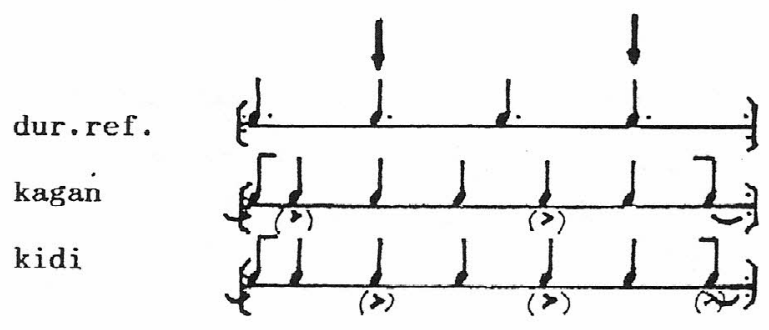


Em um destes segmentos o executante transforma o motivo " $a$ " em um modelo de periodicidade (ciclos 60-61) e o expande através da retençäo do grupo fग्री que introduz o motivo (ciclo 62). Neste momento, reforça-se a seqüência sincopada de đuração de contraste como referência individual. Note-se que a introdução do motivo "a" se dá sempre no infcio do ciclo métrico, evidenciando a orientação métrica de acordo com a fórmula padrão.

\section{Conclusão}

O conceito de duração de referência tem por finalidade substituir o termo "beat" dos estudos de língua inglesa sobre a música africana. Este termo, comum entre músicos norte-americanos, não é usado normalmente por músicos de outras nacionalidades, apontando para uma certa impropriedade cientifica em ser simplesmenté transposto para a análise de um estilo musical alheio.
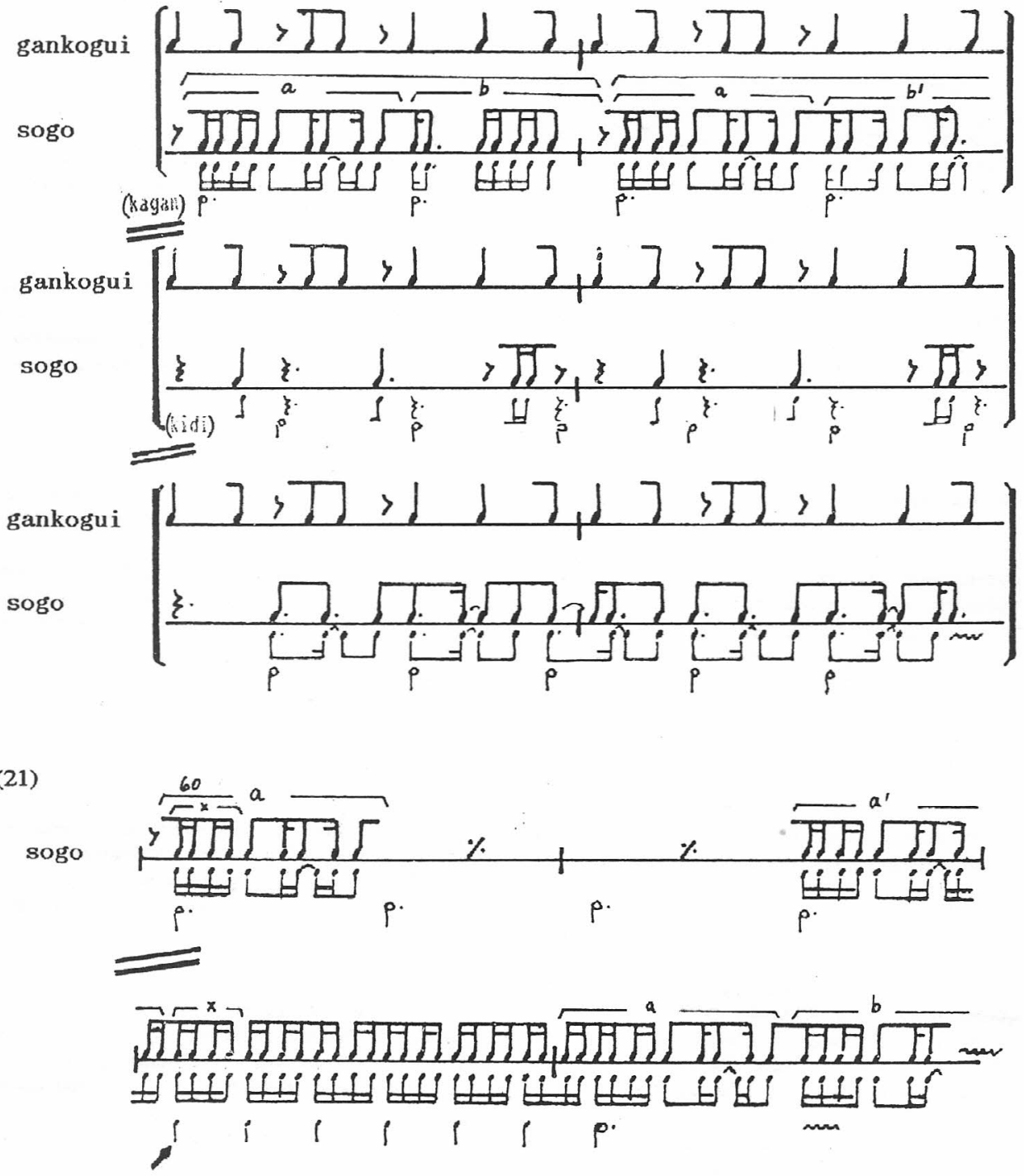
A expressão "duração de referência", mesmo que imprópria para a prática musical, possibilita ainda a identificação do fenômeno em conjunto com elementos relacionados, como as durações de contraste e divisão. Estas designações permitem ainda a sistematização dos conceitos na análise das peças que compōem um repertório africano, indiferentemente da base rítmica binária ou ternária de suas peças. (10)

A música iorubá confurma a existência de um nível de orientação rítmica, expresso pela seqüência de duração de referência. Nesta música, assim como em Agbadza e em outros exemplos do repertório ewe, é primordialmente esta duração que regula os movimentos da dança de abertura do dorso e sucessão dos passos. Nas peças ternàrias, a seqüência de duração de referência se organiza metricamente de forma quaternária $\left(4\right.$. ou $\left.\frac{12}{8}\right)$ quando associada à fórmula padrāo, como demonstram, no caso de Agbadza, as entradas regularmente na mesma posição da parte do sogo.

Com relação à legitimidade da referência mental direta dos músicos ewe à seqüência de duração de referência, as opiniōes são divergentes.(11) As partes suporte conjuntamente e a alternância da referência do executante do sogo a elas tornam latente a seqüência sincopada de duração de contraste.

Neste sentido, a alteraçāo estrutural da parte do kagan ganha relevância. Aceitando-se que o executante tenha realmente incorrido em um "lapso" no ciclo 60 , devidamente "corrigido" no ciclo 73, há que se observar que sua antecipação se dá em relação a esta seqüência. Isto $\epsilon$, o executante antecipa sua posição no ciclo métrico em uma duração sincopada de contraste, e não em um valor da seqüência de duração de referência.
Concluindo, eu gostaria de formular o exposto em um princípio de orientação e organização rítmicas das partes texturais de um conjunto instrumental da África Ocidental. Segundo este princípio, cada parte de textura estaria submetida exclusivamente às seqüências de duração de referência e de contraste em sua forma tética ou sincopada, conforme o exempio (22).

A próxima relaçâo possivel seria dada em um nível métrico individual. Isto $\epsilon$, no nível de distribuição regular de acentos dentro da respectiva seqüência de referência, como expresso nos exemplos (16-17) para o caso de Agbadza.

A diferença entre este tipo de abordagem e aquele realizado por Locke é que nele as configuraçóes de superfície poderiam ser remetidas a um nível rítmico de referência individual profundo e abstratamente limitado à disposição seqüencial de apenas duas duraçōes - a duração de referência e a de contraste. A realização tética ou sincopada destas seqüências determinaria a posição destas configuraçōes dentro do ciclo métrico.

Neste contexto, cabe mencionar a função da fórmula padrão. Por um lado, ela se subordina à projeção da duração de referência; por outro, o seu arranjo linear interno permite inferir através do seqüenciamento das três primeiras batidas a seqüência de duração de contraste em posição tética, e, através do seqüenciamento das últimas quatro batidas, a seqüência sincopada de duração de contraste.

Completando a comparação feita acima sobre os estilos iorubá e ewe, pode-se afirmar que no primeiro está excluída a referência à seqüência de duração de contraste em sua forma tética e sincopada nas partes texturais, enquanto que no segundo estas relaçốes são possíveis em caráter permanente.
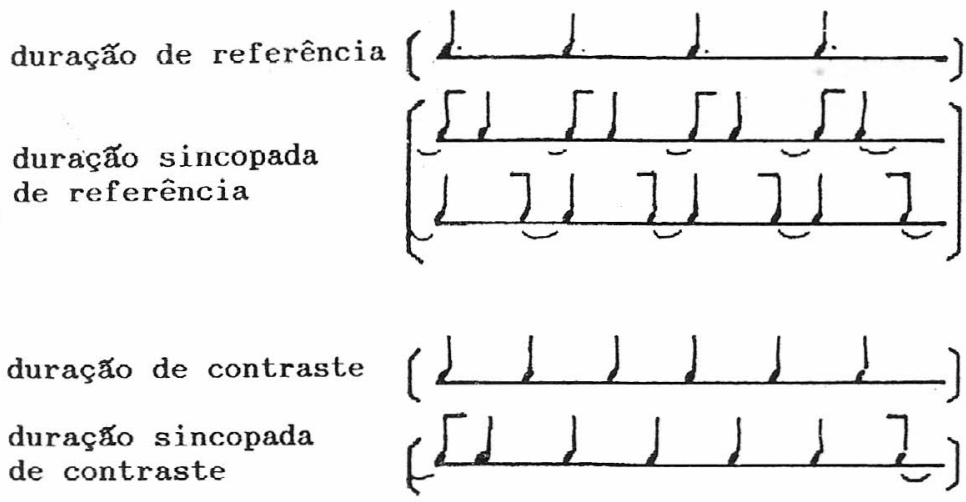


\section{Notas}

(1) Os conceitos aqui apresentados, referentes às duraçōes empregadas, foram originalmente desenvolvidos em minha dissertação de doutorado sobre a música para tambores batá nas cidades de Pobè e Sakété da República Popular do Benin (Lacerda 1988:183-5). Para uma boa retrospectiva sobre a teoria da música africana, v. Kubik (1984). Uma abordagem original, apresentada aqui parcialmente, encontra-se em Locke (1982).

(2) V discussāo a esse respeito em Pantaleoni (1972:54-56) e também as transcriçōes de Jones (1959).

(3) V. Lacerda (1988:189-95) e Locke' (1982:239-240, exemplos 21-22).

(4) Exemplo em Locke (1983:35).

5) Este estudo baseia-se em transcrição feita a partir da excelente gravaçăo de Richard Hill, com a qual me ocupei a título de preparação para uma pesquisa de campo na Africa Ocidental. Na parte do sogo, parcialmente transcrita nos exemplos 22-23, não foram consideradas as variacôes de timbre. A versão de Locke foi extraída de seu artigo (1982:235).

(6) V. Ladzekpo et al.(1980) para uma sumária descriçāo dos instrumentos ewe.

(7) A relaçāo de ritmo cruzado entre o kidi e o kagan passa desapercebida na análise de Locke (1982:233). Por outro lado, ele vê na configuração do kagan um exemplo de ritmo cruzado horizontal, no qual as duas primeiras batidas sugeririam uma divisăo em duas fases da duraçāo de referência y $\vec{\nabla} \Rightarrow \boldsymbol{D})$ e as três últimas uma divisäo temária.

Em outras palavras, Locke considera o ritmo cruzado passível de realização horizontal (a) e vertical (b).

(a)

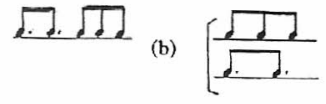

(8) A seqüência sincopada de duração de contraste é vista por Locke (1982:237) como uma forma de realização do que ele denomina de "consistent offbeat accent".

(9) Esta parece ser uma característica efetiva de Agbadza, uma vez que Pantaleoni (1972:60) faz a mesma observação sobre a atuação do sogo.

(10) Note-se que os estudos de Locke $(1982,1983)$ e Pantaleoni (1972) se referem exclusivamente às peças ternárias do repertório atsiā.

(11) V. Locke (1982:245, nota 7) e Pantaleoni (1972:54-8) para uma exposição resumida desta discussāo.

\section{Referências}

Richard Hill, Dnoms of West Africa-Ritual Music of Ghana. Lyrichord Discs, LLSt 7307. New York.

Arthur M. Jones, 1959. Studies in African Music. Londres.

Gerhardt Kubik, 1984. "Einige Grundbegriffe und - konzepte der afrikanischen Musikforschung." In Joseph Kuckertz (ed.), Jahrbuch für musikalische Volks - und Völkerkunde, 10: 57-102.

Marcos Branda Lacerda, 1988. Kultische Trommelmusik der Yoruba in der Volksrepublik Benin - Bata-Sango und Bata-Egungun in den Ständten Pobè und Sakété. Hamburgo.

Alfred Kwashie Ladzekpo \& Kobla Ladzekpo, 1980. "Anlo Ewe music in Anyako, Volta Region, Ghana." In Elizabeth May (ed.), Musics of many cultures. Berkeley e Los Angeles.

David Locke, 1982. "Principles of offbeat timing and cross-rhythm in southern Ewe dance drumming." In Ethnomusicology 26(2): 217-246.

id., 1983. "Atsiagbeko, the polyrhythmic texture." In Sonus 4: $16-38$.

Hewitt Pantaleoni, 1972. "Three principles of timing in Anlo Ewe dance drumming." In African Music 5 (2): 50-63. 